\title{
Optimal Seeking Surface Roughness and Material Removal Rate Responses of Hardened AISI 4340 High Strength Low Alloy Steel in Dry Sustainable Environment
}

\author{
Amar ul Hassan Khawaja' ${ }^{1 a}$, Mirza Jahanzaib ${ }^{1 b}$, Shahzad Zaka \\ RECEIVED ON 13.05.2019, ACCEPTED ON 23.10.2019
}

\begin{abstract}
The aim of this research is to study the machinability aspects of hardened AISI 4340 High Strength Low Alloy (HSLA) steel (50 \pm 2 HRC (Hardness Rockwell C)). The experimental investigation using coated carbide inserts is carried out during the dry hard milling process in a sustainable environment. The input parameters in the study are speed, feed rate and depth of cut and the responses are Average surface Roughness (Ra) and Material Removal Rate (MRR) that are selected through screening. Central Composite Design (CCD) in response surface methodology has been utilized as the experimental design technique with twenty experiments. Analysis of variance has been employed to examine the momentous machining parameters and responses. A mathematical model has been developed to optimize the surface roughness and material removal rate. It has been observed that the most significant factor for Ra is feed rate while for MRR depth of cut is the most significant factor. The results show that the minimum value of $R a \sim 0.098 \mu \mathrm{m}$ is achieved at speed $\sim 1000 \mathrm{RPM}$, feed rate $\sim 300 \mathrm{~mm} / \mathrm{min}$ and depth of cut $\sim 0.2 \mathrm{~mm}$ while the maximum value of $\mathrm{MRR} \sim 6.35 \mathrm{~cm}^{3} / \mathrm{min}$ is attained at feed rate $\sim 500 \mathrm{~mm} / \mathrm{min}$ and depth of cut $\sim 0.4 \mathrm{~mm}$ regarding less or no effect of speed $\sim 500-1000 \mathrm{RPM}$. The average forecast error for the validation information has been observed to be $3.35 \%$. for Ra and $3.2 \%$ for MRR. Further, it is investigated that good surface finish like grinding and dimensional accuracy can be achieved with coated carbide tools.
\end{abstract}

Keywords: High Strength Low Alloy Steel, Material Removal Rate, Multi-Objective Optimization, Sustainable Dry Machining, Surface Roughness.

\section{INTRODUCTION}

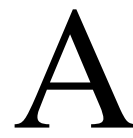
ISI 4340 is a medium carbon low alloy steel in which the combined proportion of all the alloying elements by weight is less than $5 \%$ (HSLA). It has the ability to attain high toughness and strength in the heat-treated condition. It is mostly used in the aviation industry and aeronautical applications due to very good corrosion, wear and fatigue resistance [1]. The functional performance such as corrosion resistance, fatigue strength and tribological properties of the machined components is determined by surface characteristics. The quality is determined by the surface finish and integrity attained after machining. The fatigue life of the machined parts is decreased by higher surface roughness values [2]. To accomplish quality products, certain aspects essential to be under control include process parameters, cutting tools and cutting liquids. Researchers have studied the influence of these control variables on the surface finish, material removal rate and tool wear [3-9]. For the experimental design and analysis most of the

\footnotetext{
${ }^{1}$ Department of Mechanical Engineering, University of Engineering and Technology, Taxila, Pakistan. Email: ${ }^{a}$ amar.khawaja@ @ students.uettaxila.edu.pk (Corresponding author), ${ }^{b}$ jahan.zaib@uettaxila.edu.pk.

${ }^{2}$ Department of Industrial Engineering, University of Engineering and Technology, Taxila, Pakistan. Email: shahzad.zaka@ students.uettaxila.edu.pk
}

This is an open access article published by Mehran University of Engineering and Technology, Jamshoro under CC BY 4.0 International License. 
authors have been using the statistical techniques in their experimentation.

Numerous researchers described the facts regarding the influence of process parameters on surface roughness and material removal rate during machining of AISI 4340 HSLA steel. Chakraborty et al. [10] suggested a combined effects model on end milling of AISI 4340 steel (26 HRC) under dry and minimum quantity lubrication environments using the Physical Vapour Deposition) (PVD) coated carbide inserted by selecting input machining parameters i.e feed rate $\left(\mathrm{f}_{\mathrm{r}}\right)$, depth of cut (d) and cutting speed (V) for the analysis of longitudinal data attained from a designed experiment. A tool wear progression model was developed. The lower tool life and greater tool wear was revealed at higher cutting speed and lesser tool wear and higher tool life was observed at the lower cutting speed under Minimum Quantity Lubrication (MQL) system. The depth of cut was an insignificant parameter to tool wear as followed by cutting speed and feed. Gopalsamy et al. [11] investigated the optimal milling parameters such as width of cut, V, d and $f_{r}$ for rough and finishing machining with deliberation of multiple responses, i.e. surface finish, MRR, tool life and tool wear of hardened tool steel (55 HRC) by Grey Relational Analysis (GRA) and compared the outcomes with ANOVA. It was analyzed that width of cut and cutting depth are significant factors for rough machining while to finish machining the important factor is cutting speed. Ding et al. [12] examined the impacts of radial and axial depth of cut, cutting rate and feed in hard processing of AISI H13 steel (50 HRC) utilizing coated carbide tools on $\mathrm{Ra}$ and cutting force by performing ANOVA and range analysis. It was examined that cutting force has been frustrated by two principal aspects: feed rate and axial depth of cut. The Ra achieved is less than $0.25 \mu \mathrm{m}$ which indicates that hard milling may substitute grinding. Suresh et al. [13] studied the impact of machining parameters during turning of AISI 4340 HSLA steel using coated carbide inserts to optimize $\mathrm{V}, \mathrm{d}, \mathrm{f}_{\mathrm{r}}$, machining time and Ra. Machining force and tool wear were output parameters. The Response Surface Methodology (RSM) was used for the development of a mathematical model and full factorial design was used as a design of experiments. For analyzing and selection of best machining parameters ANOVA was used. It was concluded that for the minimum value of $\mathrm{Ra}$ and machining force, lower feed rate and depth of cut with high cutting speed was required. Further, they recommended that lower feed rate and cutting speed can be used for minimum tool wear. Das et al. [14] investigated the dry turning process of 4340 HSLA steel (C 0.39\%, 47 HRC) and checked the impact of $f_{r}, V$ and $d$ on Ra with Chemical Vapour Deposition (CVD) multilayer coated carbide inserts. For experimental planning, a full factorial design of the experiment was carried-out, and ANOVA was utilized to inspect the substantial process parameters on roughness. The association among the process parameters and response multiple regression analysis was used for modeling of $\mathrm{Ra}$. It was concluded that at $95 \%$ confidence level feed was the most influencing process parameter followed by cutting speed.

An et al. [15] studied hard dry milling of 30Cr3SiNiMoVA (30Cr3) high strength steel regarding tool wear, cutting force, chip formation and surface roughness individually using coated cemented carbide tool. Taguchi L16 was selected as the experimental design technique with $\mathrm{V}, \mathrm{f}_{\mathrm{r}}$ and radial depth of cut as the process parameters. A decrease in cutting forces and improvement in the surface finish was reported with the rise of cutting speed, whilst both depths of cut and feed had an adverse influence on surface finish. Senthilkumar et al. [16] performed optimization of process parameters i.e $\mathrm{V}, \mathrm{f}_{\mathrm{r}}$ and $\mathrm{d}$ for Ra, MRR and flank wear during turning of AISI 1045 HSLA steel using CCD in RSM and compared the results with firefly algorithm. It was revealed that the substantial factor for $\mathrm{Ra}$ and flank wear is feed rate while cutting speed for MRR. Azam et al. [17] studied the impact of cutting conditions on AISI 4340 HSLA steel during turning operation using multilayer coated carbide tool and established a surface roughness model. A sequence of examinations using RSM had been carried out to mature a connection among $\mathrm{Ra}$ and turning process parameters i.e. $\mathrm{V}, \mathrm{d}$, and $\mathrm{f}_{\mathrm{r}}$. The results indicated that feed was a significant parameter that influenced the $\mathrm{Ra}$. A mathematical model was developed and it was found that the surface roughness was influenced by a feed as a core parameter. Lauro et al. [18] examined the minimum force and torque by selecting the best machining parameters combination 
(grain size, $\mathrm{V}$ and $\mathrm{f}_{\mathrm{r}}$ ) with the combination of both genetic optimization algorithm and the least squares model. The optimization of micro-milling utilizing hardened DIN 1.2344 chromium type tool steel was completed by applying the NSGA II algorithm. It was investigated that for the minimization of Force and Torque, the feed rate was the utmost substantial aspect. Hassanpour et al. [19] analyzed the hard milling of 4340 alloy steel using MQL system and explored the relationship between milling parameters i.e. $\mathrm{V}$, radial and axial depth of cut, machined surface integrity and cutting speed. The possessions of these milling parameters on chemical composition, white layer thickness, microhardness, roughness, and topography were considered through RSM. The ANOVA results showed that the linear model was suitable to assess the white layer thickness and the quadratic polynomial model was suitable to govern the microhardness and surface roughness. Further, they investigated that minimum $\mathrm{Ra}$ was attained at minimum feed and depth with maximum cutting speed.

Abbas et al. [20] examined the process parameters $\mathrm{f}_{\mathrm{r}}$, $\mathrm{d}$ and spindle speed on $\mathrm{Ra}$ and MRR for milling process of high strength steel using full factorial design technique. They established a mathematical relationship amongst the process parameters and responses using the least squares technique and a second-order regression model was constructed. ANOVA was used to check the significant machining parameters and it was observed that the feed rate had a maximum impact on Ra. Antony et al. [21] scrutinized the impacts of process parameters $V, d, f_{r}$ and nose radius on quality and productivity during turning of EN-24 alloy steel using RSM technique. Significant parameters were patterned by ANOVA and suggested that feed rate and depth of cut were substantial for MRR and cutting speed and nose radius were the significant parameters for Ra. They established an empirical relationship for calculating the Ra and MRR values at any parameter value. Kumar et al. [22] examined the impact of MQL and process parameters $\mathrm{V}, \mathrm{f}_{\mathrm{r}}$ and nose radius on surface quality by turning of AISI 4340 hardened steel with CBN cutting tool at different hardness levels i.e. 40, 45, 50, 55 and $60 \mathrm{HRC}$. The significance of machining parameters was checked by ANOVA and for the development of a mathematical model, the second-order regression technique was used for the optimum value of surface roughness. The results showed that turning of dry and wet conditions had rough surface quality as compared to MQL and $7-10 \%$ improvement in surface quality had been achieved. Khan and Bhivsane [23] evaluated the consequences of machining parameters i.e. $\mathrm{V}, \mathrm{d}, \mathrm{f}_{\mathrm{r}}$ and nose radius on hardened AISI 4340 steel (47-50 HRC) to optimize the tool wear and $\mathrm{Ra}$ as response parameters. Multiple regression technique was used for turning parameters to optimize Ra value and L9 Taguchi's method was applied as an experimental method. The results indicated that the depth of cut and feed rate had a lower impact on Ra than the cutting speed and nose radius.

Recently, Muaz and Choudhary [24] studied the machinability aspects of AISI 4340 steel using coated carbide tool and MQL technique. Milling process parameters (speed, MQL type, and feed rate) with responses force and surface roughness were optimized using Taguchi and Taguchi-GRA method respectively. It was investigated that feed rate was the most significant variable that affected the force followed by MQL type and speed while for surface roughness MQL type was the most significant variable followed by feed rate and speed. Benedicto et al. [25] explored that dry machining was the best environmental substitute and sustainable process which entirely eliminated the use of cutting fluids and ensured a clean environment and protection. As indicated by Brundtland report (1987) sustainable development is characterized as development that addresses the issues of the present generation without negotiating the capacity of future generation to address their own issues [26]. Sustainable manufacturing expects to create appropriate strategies to change over materials into completed items by diminishing utilization of earth's characteristic assets and energy, declining natural emissions and pollution, decreasing health and safety dangers, and delivering less waste, while holding the objective of better execution and economy to the clients and leaving a superior planet for our future cohort [27]. The sustainable machining model comprises eco-friendly, cost savings, energyefficient, increased tool life, waste-free, operational safety, and personal health as shown in Fig. 1. 
In the current research dry machining of AISI 4340 HSLA steel has been reported to save the future generation in the perception of sustainability that covers the three dimensions i.e. economic, social and environment. Dry machining takes out the utilization of cutting liquids and reduces $16-17 \%$ of the total machining cost (economic impact) [28, 29]. Dry machining can successfully dispense with the comfort perils like dermatitis, skin contaminations, respiratory infections, and malignancy, related to cutting liquids (social impact), and in the meantime enhance the general execution of cutting activities and there will be no need for disposal of cutting fluids (save environment) because of dry machining.

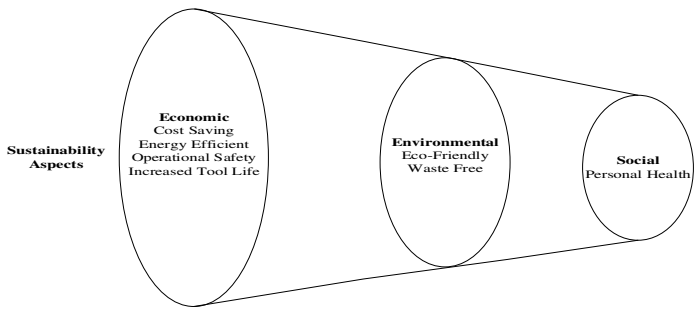

Fig. 1: Sustainable Dry Machining Model

It can be determined from the literature review that process parameters have a direct impact on surface roughness and material removal rate. It can also be inspected that by changing alloy composition and a hardness value of 4340 steel the influence of process parameters combination feed, speed and depth of cut also changed. It is ostensible from the literature that limited work has been reported on AISI 4340 HSLA steel $(50 \pm 2$ HRC) for dry hard milling operation.

The aim of current research is to investigate the influence of process parameters, the evolution of the mathematical model, and their optimization through response surface methodology. The significance of the research is the optimal parameters combination such as feed rate, cutting speed and depth of cut for hardened AISI 4340 HSLA steel with alloy composition C $0.39 \%$, Cr $0.81 \%$, Ni $1.8 \%$, Mo $0.24 \%$ having hardness value of $50 \pm 2 \mathrm{HRC}$ to achieve the better surface finish and higher material removal rate in perspective of sustainability. Analysis of variance has been applied to analyze the momentous machining parameters for dry hard milling operations. It is expected that this work would be beneficial and the contribution likely is in the field of manufacturing/ machining and for practitioning engineers.

\section{EXPERIMENTAL WORK}

This section presents the experimental details including material selection and specimen preparation, levels of process parameters and specimen machining.

\subsection{Material Selection and Specimen Preparation}

Steels are utilized monetarily in the aviation industry and aeronautical applications, establishing only 7-20 $\%$ of the aggregate weight of commercial and military airplane $[30,31]$. The steels utilized in commercial and military aircrafts are for the most part low-alloy steels, such as 4340 and $300 \mathrm{M}$ because of the higher tensile and yield strength. AISI 4340 HSLA steel is selected as a working material for the current study and alloy composition is given in Table 1 (Peoples Steel Mills Limited authenticated by QA department). The XRF analyzer and wet analysis method were used for confirmation of chemical composition before experimentation.

\begin{tabular}{|c|c|c|c|c|c|c|c|c|}
\hline Tabl & $: \mathrm{Cl}$ & mica & $\begin{array}{r}1 \text { Com } \\
\text { HS }\end{array}$ & posit & $\begin{array}{l}n(1 \\
\text { eel }\end{array}$ & & & 340 \\
\hline $\mathrm{C}$ & $\mathrm{Si}$ & $\mathrm{P}$ & $\mathrm{S}$ & $\mathrm{Cr}$ & Mo & $\mathrm{Ni}$ & $\mathrm{Cu}$ & $\mathrm{Mn}$ \\
\hline 0.39 & 0.27 & 0.015 & \begin{tabular}{|l|l|}
0.014 \\
\end{tabular} & 0.81 & 0.24 & 1.8 & 0.13 & 0.78 \\
\hline
\end{tabular}

To achieve the required hardness value $(50 \pm 2$ HRC) heat treatment of the specimens were conducted. The parameters used in heat treatment are given in Table 2. Rockwell hardness tester with diamond indenter was used to measure the hardness value. After achievement of hardness value (50 $\pm 2 \mathrm{HRC})$, the specimens were cut to the desired size of $32 \mathrm{~mm} \times 32 \mathrm{~mm} \times 20 \mathrm{~mm}$ from the bar of length $1000 \mathrm{~mm}$ using a disk cutter.

\begin{tabular}{|c|c|c|c|c|c|c|}
\hline \multicolumn{2}{|c|}{ Table 2: Heat Treatment Parameters } & \multicolumn{3}{c|}{ Tempering } \\
\hline \multicolumn{2}{|c|}{ Austenzing } & \multicolumn{2}{|c|}{ Quenching } & Time $(\mathrm{min})$ & Temperature $\left({ }^{\circ} \mathrm{C}\right)$ & Time $(\mathrm{min})$ \\
\hline Temperature $\left({ }^{\circ} \mathrm{C}\right)$ & Time $(\mathrm{min})$ & Medium & Temperature $\left({ }^{\circ} \mathrm{C}\right)$ & & \multirow{2}{*}{} \\
\hline 570 & 40 & PSO & 30 & 30 & & 120 \\
700 & 10 & Oil No. 10 & 30 & & & \\
840 & 60 & & & & & \\
\hline
\end{tabular}




\subsection{Levels of Process Variables}

The input parameters in the study are speed (V, PM), feed rate $\left(f_{r}, \mathrm{~mm} / \mathrm{min}\right)$ and depth of cut $(\mathrm{d}, \mathrm{mm})$ and responses fixed are average surface roughness $(\mathrm{Ra}$, $\mu \mathrm{m})$ and material removal rate $\left(\mathrm{MRR}, \mathrm{cm}^{3} / \mathrm{min}\right)$. Similar studies using these inputs and responses have been cited in the literature $[11,16,20,21]$. The objective is to optimize the input parameters to achieve desired response values. The level of input process parameters is given in Table 3 .

\begin{tabular}{|c|c|c|c|}
\hline \multicolumn{3}{|c|}{ Table 3: Levels of Input Process Parameters } \\
\hline \multirow{2}{*}{ Factors } & Low & Middle & High \\
\cline { 2 - 4 } & 500 & 750 & 1000 \\
\hline Speed, V (RPM) & 300 & 400 & 500 \\
\hline Feed, $\mathrm{f}_{\mathrm{r}}(\mathrm{mm} / \mathrm{min})$ & 0.2 & 0.3 & 0.4 \\
\hline Depth of cut, d $(\mathrm{mm})$ &
\end{tabular}

\subsection{Specimens Machining}

Dry hard milling tests have been performed on AISI 4340 HSLA steel in the current study. Marking has been performed on the specimens from 1-20 and experiments as per the design matrix is carried out on a CNC milling machine (DAHLIH MCV-720) using coated carbide tool as shown in Fig. 2. Now, each specimen is faced down to get machine zero points in Z-axis for setting the depth of cut value. After that, each specimen is milled using the DOE values by following Climb Milling Operation for the better surface finish. After machining all the specimens were checked for surface roughness $(\mathrm{Ra})$ value using the Mitutoyo SJ-410 surface finish measuring apparatus. The material removal rate was measured by finding the initial and final weights of specimen and machining time was also recorded with the help of stopwatch. Following expression [32] is used to compute the MRR response and results are given in Table 4.

MRR $=\frac{\text { Initial Weight of Specimen }- \text { Final Weight of Specimen }}{\text { Density } \times \text { Machining Time }}$

\section{EXPERIMENTAL DESIGN}

Central composite design in RSM has been utilized for the selection of the best process parameters combinations. The RSM cartels the mathematical and statistical methods to establish the response when aspects are diverse coincidentally. The outcomes were

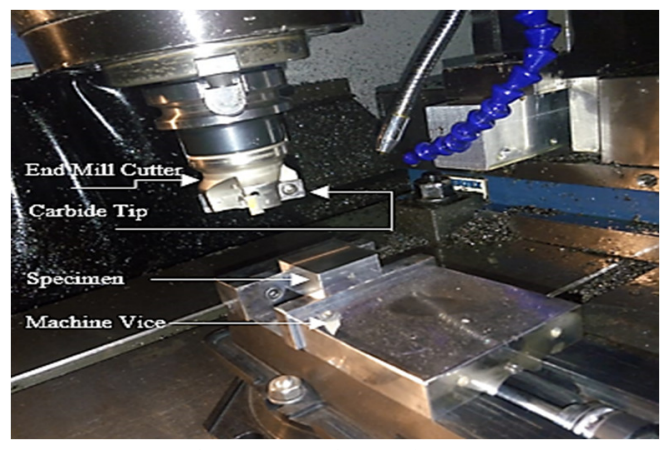

Fig. 2: Experimental Setup

demonstrated to fit either a first or second-order model characterized by the following relations Eq. $(2,3)$ [17]:

$$
\begin{gathered}
y=\beta_{0}+\beta_{1} x_{1}+\beta_{k} x_{k}+\varepsilon \\
y=\beta_{0}+\sum_{\mathrm{i}=1} \beta_{\mathrm{i}} \mathrm{x}_{\mathrm{i}}+\sum \beta_{\mathrm{ii}} \mathrm{x}_{\mathrm{i}}^{2}+\sum \sum_{\mathrm{j}<1} \beta_{\mathrm{i}} \mathrm{j}^{\mathrm{x}_{\mathrm{i}} \mathrm{x}_{\mathrm{j}}} \\
+\varepsilon
\end{gathered}
$$

where $\beta_{0}, \beta_{\mathrm{i}}, \beta_{\mathrm{ii}}$ and $\beta_{\mathrm{ij}}$ are called parameters of approximating functions, $\mathrm{y}$ is performance variable and $x_{i}$ is input variable.

Central composite design in RSM is the most prominent second-order design which was presented by Box and Wilson. The CCD is a factorial outline with center and star points. The estimation of star points is indicated by curvature. The factorial plan is designated in CCD to contribute the approximation of the interaction terms. The axial points subsidize large to the estimation of quadratic terms. The aggregate of the quadratic relations can be evaluated without the axial points. The factorial focuses do not add to the approximation of quadratic relations. The middle runs to give an inside estimate of error and subsidize toward the assessment of quadratic relations. The regions of adaptability in the utilization of CCD reside in the determination of axial distance $(\alpha \sim 1.68)$ and the number of center runs $\left(\mathrm{n}_{\mathrm{c}}\right)$. The decision of $\mathrm{n}_{\mathrm{c}}$ frequently influences the distribution of variance in the region of intrigue. The axial distance esteem $\alpha$ is kept up rotatability and it relies upon the quantity of test keeps running in the factorial bit of the central composite design [33]. In this work, twenty experimental design points were considered according to design equation $2^{n}+2 n+2 n_{c}$ ( $n$ is the number of 
input parameters) including eight factorial points $\left(2^{\mathrm{n}}\right)$, six axial points $(2 \mathrm{n})$ and six center points $\left(2 \mathrm{n}_{\mathrm{c}}\right)$ as shown in Fig. 3 [34, 35].

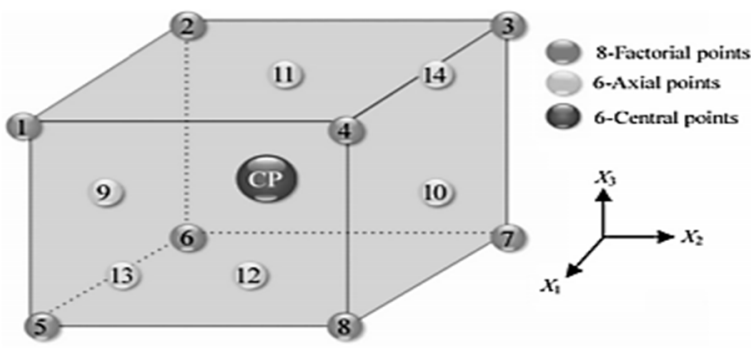

Fig. 3: CCD Points Location for 3 Parameters

\section{RESULTS AND DISCUSSION}

Design of Experiment (DOE) matrix has been developed through design expert 7. The experimental results with complete DOE are given in Table 4 . It has been observed that minimum value of $\mathrm{Ra} \sim 0.098 \mu \mathrm{m}$ is achieved with process parameters combinations cutting speed $\sim 1000 \mathrm{RPM}$, feed rate $\sim 300 \mathrm{~mm} / \mathrm{min}$ and depth of cut $\sim 0.2 \mathrm{~mm}$ while maximum value of $\mathrm{MRR} \sim$ has been attained at feed rate $\sim 500 \mathrm{~mm} / \mathrm{min}$, depth of cut $\sim 0.4 \mathrm{~mm}$ and cutting speed $\sim 500-1000$ RPM.

\subsection{Statistical Analysis}

The RSM has been performed to predict Ra and MRR in the dry hard milling of 4340 HSLA steel using a shell end mill type cutter with carbide inserts attached to it. Table 5 (a-b) delivers the statistical model summary for Ra and MRR. It is apparent from Table 5 (a) that the quadratic model is best recommended for $\mathrm{Ra}$ and two-factor interaction model is best suited for MRR; along these lines, it has been utilized for advance examination.

\begin{tabular}{|c|c|c|c|c|c|}
\hline \multicolumn{6}{|c|}{ Table 4: Design Matrix With Responses } \\
\hline \multirow[b]{2}{*}{ Standard } & \multicolumn{3}{|c|}{ Input machining parameters } & \multicolumn{2}{|c|}{ Responses } \\
\hline & $\begin{array}{c}\text { Cutting Speed } \\
\text { RPM }\end{array}$ & $\begin{array}{c}\text { Feed rate } \\
\mathrm{mm} / \mathrm{min}\end{array}$ & $\begin{array}{c}\text { Depth of cut } \\
\mathrm{mm}\end{array}$ & $\begin{array}{c}\mathrm{Ra} \\
\mu \mathrm{m}\end{array}$ & $\begin{array}{c}\text { MRR } \\
\mathrm{cm}^{3} / \mathrm{min}\end{array}$ \\
\hline 1 & 500 & 300 & 0.2 & 0.169 & 1.83 \\
\hline 2 & 1000 & 300 & 0.2 & 0.098 & 1.96 \\
\hline 3 & 500 & 500 & 0.2 & 0.221 & 3.25 \\
\hline 4 & 1000 & 500 & 0.2 & 0.193 & 4.63 \\
\hline 5 & 500 & 300 & 0.4 & 0.196 & 4.92 \\
\hline 6 & 1000 & 300 & 0.4 & 0.148 & 3.87 \\
\hline 7 & 500 & 500 & 0.4 & 0.251 & 6.35 \\
\hline 8 & 1000 & 500 & 0.4 & 0.255 & 6.35 \\
\hline 9 & 329.5 & 400 & 0.3 & 0.227 & 4.31 \\
\hline 10 & 1170.4 & 400 & 0.3 & 0.147 & 3.84 \\
\hline 11 & 750 & 231.8 & 0.3 & 0.153 & 2.61 \\
\hline 12 & 750 & 568.2 & 0.3 & 0.265 & 5.91 \\
\hline 13 & 750 & 400 & 0.132 & 0.154 & 2.23 \\
\hline 14 & 750 & 400 & 0.468 & 0.203 & 5.91 \\
\hline 15 & 750 & 400 & 0.3 & 0.212 & 4.46 \\
\hline 16 & 750 & 400 & 0.3 & 0.209 & 4.35 \\
\hline 17 & 750 & 400 & 0.3 & 0.197 & 3.92 \\
\hline 18 & 750 & 400 & 0.3 & 0.213 & 3.91 \\
\hline 19 & 750 & 400 & 0.3 & 0.202 & 3.92 \\
\hline 20 & 750 & 400 & 0.3 & 0.207 & 3.87 \\
\hline
\end{tabular}

\begin{tabular}{|c|c|c|c|c|c|c|}
\hline \multicolumn{7}{|c|}{ Table 5 (a): Model Summary Statistics for Ra } \\
\hline Source & Std. dev & R-Squared & Adjusted R-Squared & Predicted R-Squared & PRESS & \\
\hline Linear & 0.0159 & 0.8751 & 0.8516 & 0.7890 & 0.0068 & \\
\hline 2FI & 0.0139 & 0.9224 & 0.8865 & 0.8166 & 0.0059 & \\
\hline Quadratic & 0.0074 & 0.9829 & 0.9676 & 0.9058 & 0.0030 & Suggested \\
\hline Cubic & 0.0056 & 0.9941 & 0.9813 & 0.9779 & 0.0007 & Aliased \\
\hline
\end{tabular}

\begin{tabular}{|c|c|c|c|c|c|c|}
\hline \multicolumn{7}{|c|}{ Table 5(b): Model Summary Statistics for MRR } \\
\hline Source & Std. dev & R-Squared & Adjusted R-Squared & Predicted R-Squared & PRESS & \\
\hline Linear & 0.3612 & 0.9392 & 0.9278 & 0.8942 & 3.6304 & \\
\hline 2FI & 0.2153 & 0.9824 & 0.9743 & 0.9597 & 1.3811 & Suggested \\
\hline Quadratic & 0.2314 & 0.9844 & 0.9703 & 0.9425 & 1.9740 & \\
\hline Cubic & 0.2385 & 0.9901 & 0.9685 & 0.9849 & 0.5175 & Aliased \\
\hline
\end{tabular}




\subsection{Quadratic Model}

The CCD was utilized to develop the mathematical relationship for associating the surface roughness $(\mathrm{Ra})$ as a response and process parameters $(\mathrm{V}, \mathrm{f}$, and $\mathrm{d})$. Equation (4) is used to analyze the response at any value of the input parameter.

$\mathrm{R}_{\mathrm{a}}=0.16028-1.90940 \mathrm{E}-4 \mathrm{~V}-1.27734 \mathrm{E}-$ $4 \mathrm{f}+0.49028 \mathrm{~d}+4.75000 \mathrm{E}-7 \mathrm{Vf}+2.75000 \mathrm{E}-$ $4 \mathrm{Vd}+1.87500 \mathrm{E}-4 \mathrm{fd}-1.08567 \mathrm{E}-4 \mathrm{Vd}+$ $1.87500 \mathrm{E}-4 \mathrm{fd}-1.08567 \mathrm{E}-7 \mathrm{~V}^{2}+9.92725 \mathrm{E}-$ $8 f^{2}-0.97907 d^{2}$

ANOVA for the response surface roughness quadratic model is given in Table 6. The $\mathrm{p}$-value is less than 0.05 shows the model is significant. The main significant terms are cutting speed, feed rate and depth of cut and interacting significant terms are $\mathrm{AB}$ (cutting speed $\times$ feed rate) and $A C$ (cutting speed $\times$ depth of cut) and quadratic significant terms are $\mathrm{A}^{2}$ (cutting speed ${ }^{2}$ ) and $\mathrm{C}^{2}$ (depth of cut $^{2}$ ) while values greater than 0.1000 demonstrate the model terms are insignificant to have been avoided. Interaction effects signify the shared effects of input parameters on responses. During the interaction effect, the influence of one parameter depends on the level of the other parameter. It is the ability of ANOVA to estimate the interaction effects. It is obvious that the most significant factor influencing the $\mathrm{Ra}$ is feed rate followed by the cutting speed and depth of cut. The value of the $\mathrm{R}^{2}$ statistic i.e coefficient of determination illustrates that $98.3 \%$ of the total variations are described by the model. The estimation of $\mathrm{R}^{2}$ got in the wake of changing for the extent of the model is $96.7 \%$. Examination of $\mathrm{R}^{2}$ adj $=$ 0.967 with $\mathrm{R}_{\text {pre }}^{2}=90.6 \%$ demonstrates that the two terms are in great concurrence with one another and model would be relied upon to clarify $90.6 \%$ variability in a new data. Enhanced accuracy and dependability of test outcomes is appeared by the low estimation of the coefficient of variety (C.V) which is $3.8 \%$.

\begin{tabular}{|c|c|c|c|c|c|}
\hline \multicolumn{7}{|c|}{ Table 6: ANOVA for Response Surface Roughness Quadratic Model } \\
\hline Source & Sum of Squares & df & Mean Square & F Value & p-value Prob $>$ F \\
\hline Model & 0.0319 & 9 & 0.0035 & 63.9737 & $<0.0001$ \\
\hline A-Cutting Speed & 0.0056 & 1 & 0.0056 & 101.8669 & $<0.0001$ \\
\hline B-Feed rate & 0.0181 & 1 & 0.0181 & 327.1255 & $<0.0001$ \\
\hline C-Depth of cut & 0.0046 & 1 & 0.0046 & 83.5851 & $<0.0001$ \\
\hline AB & 0.0011 & 1 & 0.0011 & 20.3741 & 0.0011 \\
\hline AC & 0.0004 & 1 & 0.0004 & 6.8290 & 0.0259 \\
\hline BC & $2.8125 \mathrm{E}-05$ & 1 & $2.8125 \mathrm{E}-05$ & 0.5079 & 0.4923 \\
\hline A $^{2}$ & 0.0007 & 1 & 0.0007 & 11.9834 & 0.0061 \\
\hline B $^{2}$ & $1.42024 \mathrm{E}-05$ & 1 & $1.42024 \mathrm{E}-05$ & 0.2565 & 0.6235 \\
\hline Residual & 0.0014 & 1 & 0.0014 & 24.9487 & 0.0005 \\
\hline Lack of Fit & 0.0006 & 10 & $5.53704 \mathrm{E}-05$ & & \\
\hline Pure Error & 0.0004 & 5 & $7.28742 \mathrm{E}-05$ & 1.9245 & 0.2449 \\
\hline Cor Total & 0.0002 & 5 & $3.78667 \mathrm{E}-05$ & & \\
\hline Std. Dev. & 0.0324 & 19 & & & \\
\hline Mean & 0.0074 & & R-Squared & 0.9829 & \\
\hline C.V. $\%$ & 0.196 & & Adj R-Squared & 0.9675 & \\
\hline PRESS & 3.7965 & & Pred R-Squared & 0.9058 & \\
\hline
\end{tabular}

\subsection{Two-Factor Interaction Model}

The material removal rate was significant at two-factor interaction (2F1) model with $\mathrm{R}^{2}=0.9824$ or close to 1 , indicating that the better the correlation between the observed and predicted values. The ANOVA for the model is shown in Table 7 and is expressed in the following equation.

$$
\begin{aligned}
& \mathrm{MRR}=-2.99279-8.56784 \mathrm{E}-004 \mathrm{~V}+ \\
& 1.97170 \mathrm{E}-003 \mathrm{f}+22.22232 \mathrm{~d}+1.15000 \mathrm{E}- \\
& 005 \mathrm{Vf}-0.012800 \mathrm{Vd}-2.25000 \mathrm{E}- \\
& 003 \mathrm{fd}
\end{aligned}
$$

From Table 7, it is apparent that the main significant terms are feed rate and depth of cut and interacting significant terms are $\mathrm{AB}$ (cutting speed $\times$ feed rate) and AC (cutting speed $\times$ depth of cut). Depth of cut is 


\begin{tabular}{|c|c|c|c|c|c|}
\hline \multicolumn{6}{|c|}{ Table 7: Anova For Material Removal Rate 2F1 Model } \\
\hline Source & Sum of squares & df & Mean Square & F Value & p-value Prob $>F$ \\
\hline Model & 33.7026 & 6 & 5.6171 & 121.2120 & $<0.0001$ \\
\hline A-Cutting Speed & 0.0080 & 1 & 0.0080 & 0.1725 & 0.6846 \\
\hline B-Feed rate & 13.4438 & 1 & 13.4438 & 290.1057 & $<0.0001$ \\
\hline C-Depth of cut & 18.7662 & 1 & 18.7662 & 404.9593 & $<0.0001$ \\
\hline $\mathrm{AB}$ & 0.6612 & 1 & 0.6612 & 14.2692 & 0.0023 \\
\hline $\mathrm{AC}$ & 0.8192 & 1 & 0.8192 & 17.6776 & 0.0010 \\
\hline $\mathrm{BC}$ & 0.0040 & 1 & 0.0040 & 0.0874 & 0.7722 \\
\hline Residual & 0.6024 & 13 & 0.0463 & & \\
\hline Lack of Fit & 0.2613 & 8 & 0.03267 & 0.4789 & 0.8306 \\
\hline Pure Error & 0.3411 & 5 & 0.06822 & & \\
\hline Cor Total & 34.305 & 19 & & & \\
\hline Std. Dev. & 0.2153 & & R-Squared & 0.9824 & \\
\hline Mean & 4.12 & & Adj R-Squared & 0.9743 & \\
\hline C.V. $\%$ & 5.2250 & & Pred R-Squared & 0.9597 & \\
\hline PRESS & 1.3811 & & Adeq Precision & 34.5003 & \\
\hline
\end{tabular}

the most significant parameter that influence MRR followed by cutting speed and feed rate. Enhanced accuracy and consistency of test outcomes is shown by the low value of the Coefficient of Variation (C.V) which comes out to be $5.2 \%$.

\subsection{Residual Analysis}

Residual analysis is the principal investigative tool to check the suitability of the proposed model [36]. The normal plot of the residuals, internally studentized residuals vs normal $\%$ probability and actual vs predicted values of Ra and MRR are shown in Fig. 4 (a-b) and Fig.5 (a-b) respectively. It is obvious from Fig. 2 that values lie near a straight line which demonstrates that mistakes are freely and typically dispersed, and presumptions are not damaged. Figure 3 demonstrates that errors are distributed regularly because points lie on a straight line in actual versus predicted plot. It is found that the model best fit the desired outcomes.

\subsection{Optimization of Surface Roughness}

Three-dimension response and contour plot of surface roughness versus cutting speed and feed rate is shown in Fig. 6. It is imperative that the Ra of the specimen is increased by increasing the feed rate and decreased by increasing the cutting speed. Further, it has been investigated that at origin value of feed rate with increasing cutting speed the Ravalue decreased and

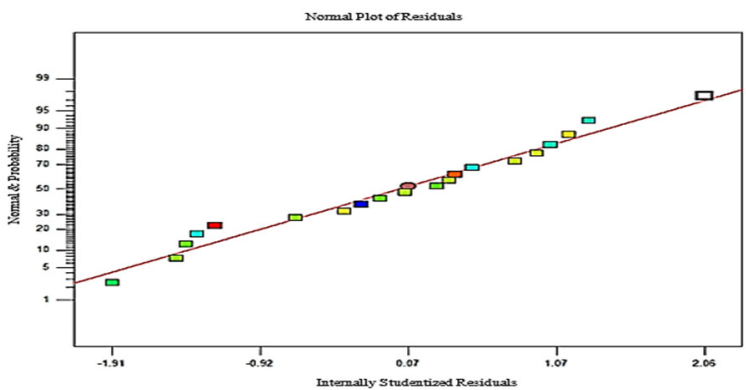

(a)

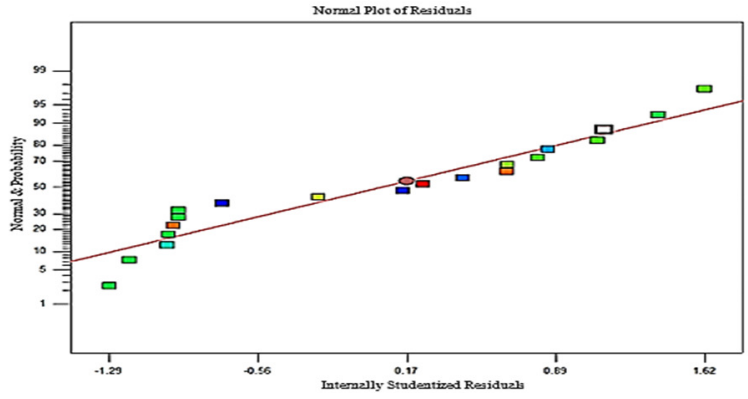

(b)

Fig. 4: Normal Plot of Residuals for (a) Ra and (b) MRR

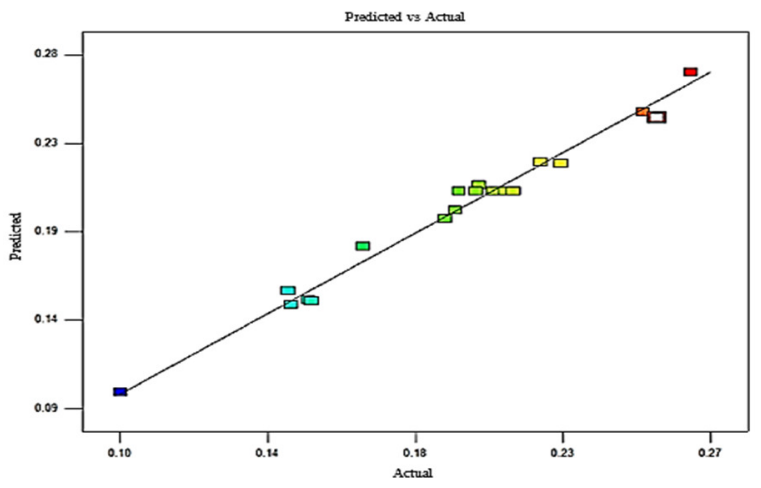

(a) 


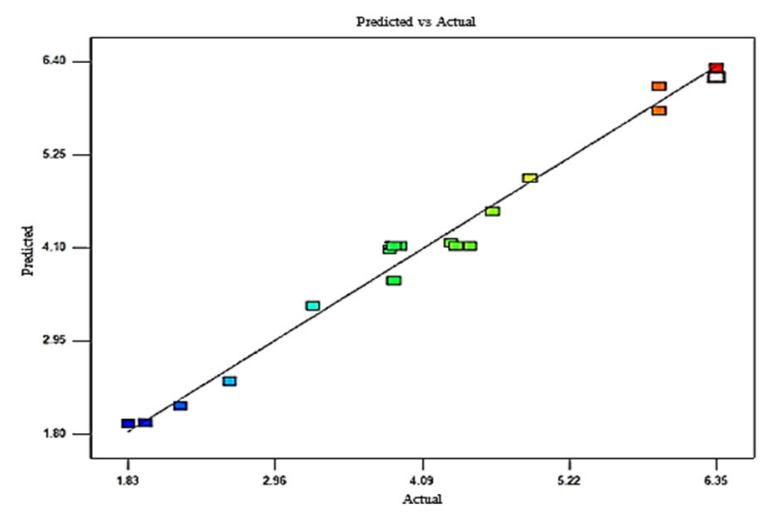

(b)

Fig. 5: The plot of Predicted Vs Actual for (a) Ra and (b) MRR

the initial value of cutting speed with increasing feed rate the $\mathrm{Ra}$ value increases. But at higher values of feed rate and cutting speed the Ra value is greater it is concluded that at a higher value of cutting speed and lower value of feed rate the $\mathrm{Ra}$ is minimum as shown in the contour plot of $\mathrm{Ra}$ versus feed rate and cutting speed. From the contour plot, the minimum Ra value is $0.152 \mu \mathrm{m}$ is attained at a cutting speed of $925 \mathrm{RPM}$ and feed rate of $316 \mathrm{~mm} / \mathrm{min}$. The Ra value is useful
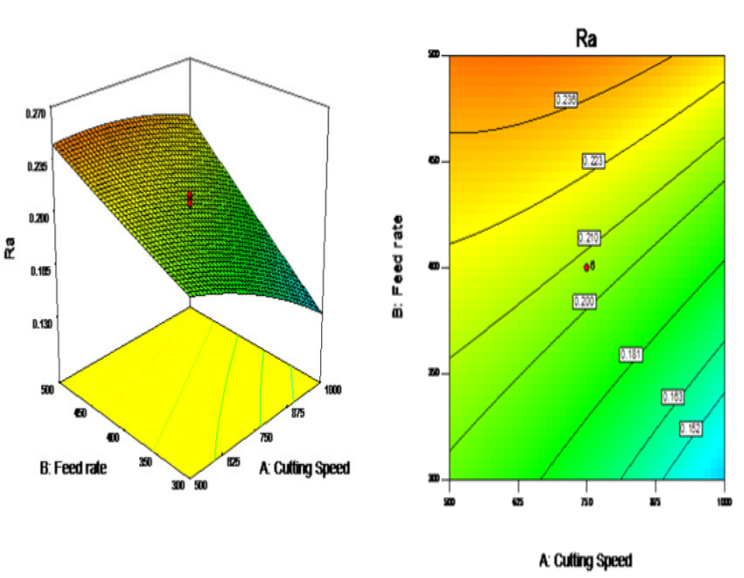

Fig. 6: 3D Response and Contour plot of Surface Roughness Vs Cutting Speed and Feed Rate

Fig. 7 shows the 3D response and contour plot of $\mathrm{Ra}$ versus cutting speed and depth of cut. It is analyzed that as cutting speed increases $\mathrm{Ra}$ decreases significantly and when the depth of cut increases Ra value also increases. Further investigated that at a lower value of the depth of cut with the increasing cutting speed the Ra decreases and at a lower value of cutting speed with increasing depth of cut Ra increases but at higher values of cutting speed and depth of cut Ra value also increases. It is concluded that at a lower value of the depth of cut with the increasing cutting speed the Ra decreases. Contour plot of $\mathrm{Ra}$ versus cutting speed and depth of cut shows that minimum Ra value of $0.152 \mu \mathrm{m}$ is achieved at cutting speed of 985 RPM with the depth of cut $0.21 \mathrm{~mm}$.

Three-dimension response and contour plot of $\mathrm{Ra}$ versus feed rate and depth of cut is shown in Fig. 8. It shows the increasing trend of surface roughness value either increasing feed rate or depth of cut. Further, it has been investigated that at a lower value of feed rate and depth of cut $\mathrm{Ra}$ is minimum. The contour plot of $\mathrm{Ra}$ versus feed rate and depth of cut shows that minimum $\mathrm{Ra}$ value of $0.152 \mu \mathrm{m}$ is attained at a feed rate of $310 \mathrm{~mm} / \mathrm{min}$ with the depth of cut $0.21 \mathrm{~mm}$.
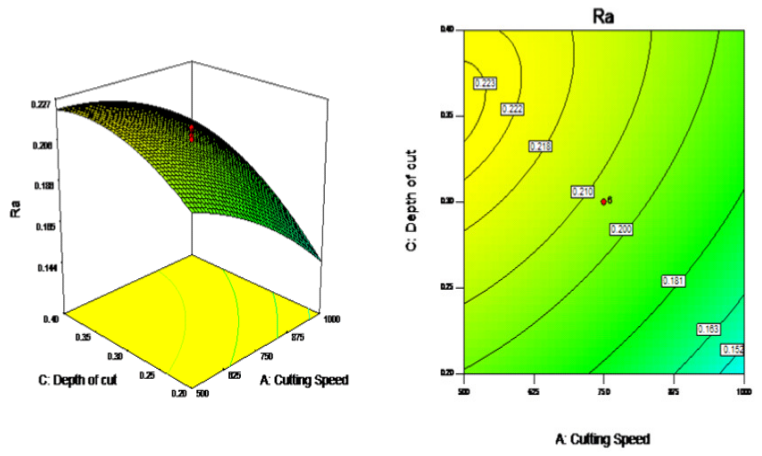

Fig. 7: 3D Response and Contour Plot of Surface Roughness Vs Cutting Speed and Depth of Cut
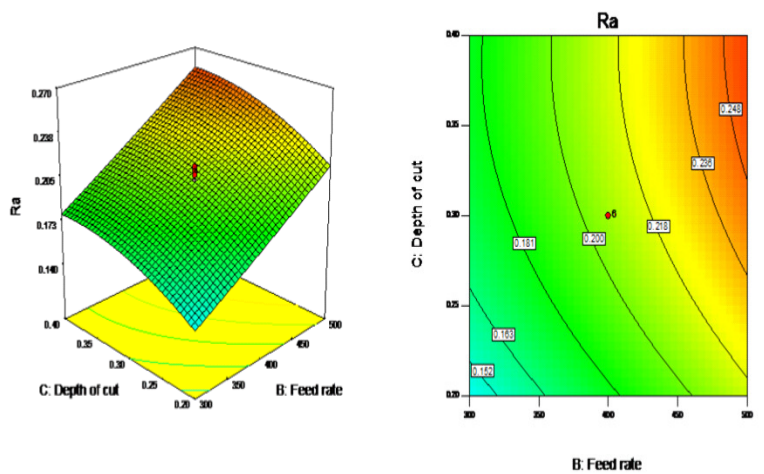

Fig. 8: 3D Response and Contour plot of Surface Roughness Vs Feed Rate and Depth of Cut

The results of the current study are compared by Muhammad Muaz and Sounak Kumar Choudhary's study [24], it is concluded that better results were achieved using dry machining then MQL technique. 


\subsection{Optimization of Material Removal Rate}

Three-dimension response and contour plot of material removal rate versus cutting speed and feed rate are shown in Fig. 9. It shows when the cutting speed increases with the initial value of the feed rate the MRR will be decreased negligibly. Further investigated that by increasing the feed rate with the initial value of cutting speed the MRR increases significantly. When both cutting speed and feed rate increases MRR will also be increased most significantly. The contour plot of MRR versus cutting speed and feed rate shows that the maximum value of $4.95 \mathrm{~cm}^{3} / \mathrm{min}$ MRR is attained at cutting speed of 784 RPM with a feed rate of $481 \mathrm{~mm} / \mathrm{min}$.
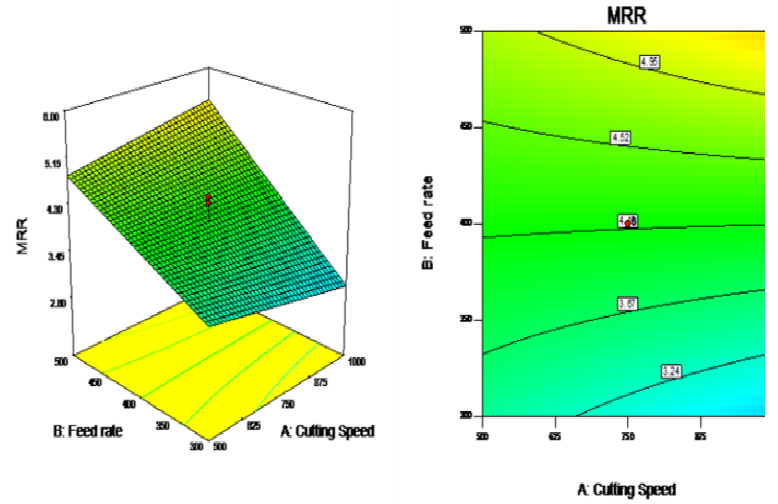

Fig. 9: 3D Response and Contour plot of Material Removal Rate Vs Cutting Speed and Feed Rate

Fig. 10 depicts the 3D response and contour plot of MRR versus cutting speed and depth of cut. It is explored that at an initial value of the depth of cut with increasing cutting speed, MRR increases and at an initial value of cutting speed with the increase of depth of cut, MRR increases most significantly. It is also investigated that by increasing cutting speed and depth of cut, MRR will also be increased but the maximum value of MRR is achieved at a lower value of cutting speed and higher value of the depth of cut. The contour plot of MRR versus cutting speed and depth of cut shows that the maximum value of $5.14 \mathrm{~cm}^{3} / \mathrm{min}$ is achieved at the cutting speed of 693 RPM and depth of cut of $0.38 \mathrm{~mm}$.

Three-dimension response and contour plot of material removal rate versus feed rate and depth of cut are shown in Fig. 11. It is examined that an initial value of the depth
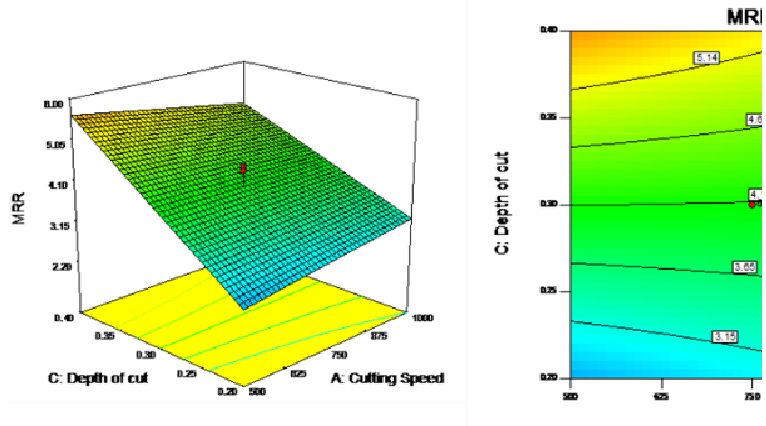

A cutting

Fig. 10: 3D Response and Contour pot of Material Removal Rate Vs Cutting Speed and Depth of Cut

value of the depth of cut with increasing feed rate the MRR will be increased suggestively and vice versa. Further concluded that when both feed rate and depth of cut increases MRR will increase most significantly and the maximum value of MRR is achieved at higher values of feed rate and depth of cut. The contour plot of material removal rate versus feed rate and depth of cut shows that maximum value of $5.54 \mathrm{~cm}^{3} / \mathrm{min}$ is achieved at the feed rate of $463 \mathrm{~mm} / \mathrm{min}$ and depth of cut of $0.37 \mathrm{~mm}$.
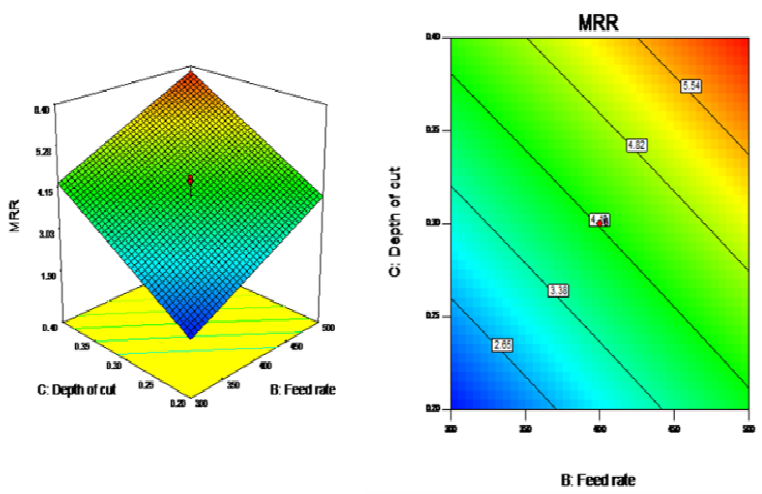

Fig. 11: 3D Response and Contour plot of Material Removal Rate Vs Feed Rate and Depth of Cut

\subsection{Validation of Model}

The model has been validated by an additional eight experiments. These trial runs do not have a place with the CCD informational index. The correctness of the model is determined through the connection given by Azam et al. [17] as given in Eq. (6). Table 8 demonstrates the experimental and predicted qualities for Ra and MRR of examinations. It is obvious from Table 8 that both experimental and predicted values coordinate intimately with one another. 
$\Delta=\frac{100}{\mathrm{~N}} \sum_{\mathrm{i}=1}^{\mathrm{N}}\left|\frac{\mathrm{y}_{\mathrm{i} \text {,experimental }}-\mathrm{y}_{\mathrm{i}, \text { predicted }}}{\mathrm{y}_{\mathrm{i}, \text { predicted }}}\right|$

The average forecast error for the validation information has been observed to be $3.35 \%$. for $\mathrm{Ra}$ and $3.2 \%$ for MRR be a good technical database for the aviation industry and aeronautical applications in machining perspectives.

Finally, it will be concluded that using model equations it will be possible to predict the Ra and MRR value of any input before conducting machining. The optimal values of the current study for Ra and MRR are given in Table 9.

\section{CONCLUSION}

The study of AISI 4340 HSLA medium carbon steel $(\mathrm{C}=0.39 \%$ with $50 \pm 2 \mathrm{HRC}$ ) has been explored to discover the optimum value of Ra and MRR by using the multi insert shell end mill type cutter. The conclusions pinched from the series of experimentations and consequent investigation of results are as follows.

(i) The outcomes specify that the quadratic model is better for Ra and 2FI model is better for MRR with maximum prediction accuracy and is confirmed through further experimentations.

(ii) After experimentation and analysis, it is investigated that $\mathrm{Ra}=0.098 \mu \mathrm{m}$ value is minimum at highest cutting speed with the combination of lowest feed rate and depth of cut i.e $1000 \mathrm{RPM}, 300 \mathrm{~mm} / \mathrm{min}$ and $0.2 \mathrm{~mm}$. Further, investigated that production rate will be maximum $\mathrm{MRR}=6.35 \mathrm{~cm}^{3} / \mathrm{min}$ at the highest value of feed rate $500 \mathrm{~mm} / \mathrm{min}$ and depth of cut 0.4 $\mathrm{mm}$ regarding less or no effect of cutting speed 500-1000 RPM.

The results achieved mainly helpful for the practitioner in the aviation and aeronautical applications to select the appropriate process parameters for achieving better quality and higher productivity. The evolutionary techniques can be explored further for investigation of AISI 4340 steel.

\section{ACKNOWLEDGEMENT}

Authors take this opportunity to record a deep sense of gratitude and appreciation to Peoples Steel Mills Limited, who provided the best quality material with accurate chemical composition. Authors also highly obliged to the management of University of Engineering \& Technology Taxila, Pakistan and Wah Engineering College, University of Wah, Pakistan, giving us the opportunity for experimentation and testing in their workshops and laboratories.

\section{REFRENCES}

[1] Maity S.K., Kawalla R., "Heat Tranfer Engineering Applications", InTech, Croatia, 2011.

[2] Sharma V.S., Dhiman S., Sehgal R., Sharma S.K., "Estimation of cutting forces and surface roughness for hard turning using neural networks", Journal of Intelligent Manufacturing, Vol. 19, No. 4, pp. 473-483, 2008.

[3] Lou S.-J. and Chen J. C., "In-process surface roughness recognition (ISRR) system in endmilling operations", The International Journal of Advanced Manufacturing Technology, Vol. 15, No. 3, pp. 200-209, 1999.

[4] Asiltürk I., Akkuş H., "Determining the effect of cutting parameters on surface roughness in hard turning using the Taguchi method", Measurement, Vol. 44, No. 9, pp. 1697-1704, 2011.

[5] Lalwani, D. I., Mehta, N. K. and Jain, P.K., "Experimental investigations of cutting parameters influence on cutting forces and surface roughness in finish hard turning of MDN250 steel", Journal of Materials Processing Technology, Vol. 206, No. 1-3, pp. 167-179, 2008.

[6] Neşeli S., Yaldız S., Türkeş E., "Optimization of tool geometry parameters for turning operations based on the response surface methodology", Measurement, Vol. 44, No. 3, pp. 580-587, 2011. 
Table 8: Validation Data

\begin{tabular}{|c|c|c|c|c|c|c|c|c|c|c|c|}
\hline \multirow{4}{*}{ Std } & \multicolumn{3}{|c|}{ Input machining parameters } & \multicolumn{8}{|c|}{ Responses } \\
\hline & \multirow{3}{*}{$\begin{array}{c}\text { Cutting Speed } \\
\text { RPM }\end{array}$} & \multirow{3}{*}{$\begin{array}{c}\text { Feed rate } \\
\mathrm{mm} / \mathrm{min}\end{array}$} & \multirow{3}{*}{$\begin{array}{c}\text { Depth of cut } \\
\mathrm{mm}\end{array}$} & \multirow{2}{*}{\multicolumn{4}{|c|}{$\begin{array}{r}\mathrm{Ra} \\
\mu \mathrm{m}\end{array}$}} & \multirow{2}{*}{\multicolumn{4}{|c|}{$\begin{array}{c}\text { MRR } \\
\mathrm{cm} 3 / \mathrm{min}\end{array}$}} \\
\hline & & & & & & & & & & & \\
\hline & & & & Actual & Predicted & Residual & Error\% & Actual & Predicted & Residual & Error\% \\
\hline 1 & 960 & 310 & 0.15 & 0.126 & 0.12 & 0.006 & 5 & 2.525 & 2.395 & 0.13 & 5.4 \\
\hline 2 & 990 & 305 & 0.25 & 0.138 & 0.132 & 0.006 & 4.5 & 2.691 & 2.676 & 0.015 & 1 \\
\hline 3 & 900 & 320 & 0.2 & 0.151 & 0.16 & -0.009 & 5.6 & 2.999 & 2.96 & 0.039 & 2 \\
\hline 4 & 960 & 360 & 0.25 & 0.168 & 0.172 & -0.004 & 2.3 & 3.718 & 3.525 & 0.193 & 5.5 \\
\hline 5 & 800 & 380 & 0.24 & 0.177 & 0.18 & -0.003 & 2 & 5.134 & 5.22 & -0.086 & 2 \\
\hline 6 & 800 & 370 & 0.27 & 0.197 & 0.204 & -0.007 & 3.4 & 4.349 & 4.09 & 0.259 & 6.3 \\
\hline 7 & 600 & 460 & 0.34 & 0.221 & 0.223 & -0.002 & 1 & 5.71 & 5.785 & -0.075 & 1.3 \\
\hline 8 & 500 & 490 & 0.35 & 0.247 & 0.24 & 0.007 & 3 & 5.621 & 5.502 & 0.119 & 2 \\
\hline
\end{tabular}

\begin{tabular}{|c|c|c|c|c|c|c|c|c|}
\hline \multicolumn{9}{|c|}{ Table 9: Optimal Response Values with Optimal Process Parameters } \\
\hline \multirow{3}{*}{ Sr. No. } & \multicolumn{6}{|c|}{ Controllable Process Parametric Values } & \multirow{3}{*}{ Response } & \multirow{3}{*}{$\begin{array}{c}\text { Optimal Response } \\
\text { Value }\end{array}$} \\
\hline & \multicolumn{2}{|c|}{ V vs f } & \multicolumn{2}{|c|}{ V vs d } & \multicolumn{2}{|c|}{ f vs d } & & \\
\hline & $\mathrm{V}$ (RPM) & $\mathrm{f}(\mathrm{mm} / \mathrm{min})$ & V (RPM) & $\mathrm{d}(\mathrm{mm})$ & $\mathrm{f}(\mathrm{mm} / \mathrm{min})$ & $\mathrm{d}(\mathrm{mm})$ & & \\
\hline 1 & 925 & 316 & - & - & - & - & \multirow{3}{*}{$\operatorname{Ra}(\mu \mathrm{m})$} & 0.152 \\
\hline 2 & - & - & 985 & 0.21 & - & - & & 0.152 \\
\hline 3 & - & - & - & - & 310 & 0.21 & & 0.152 \\
\hline 4 & 784 & 481 & - & - & - & - & \multirow{3}{*}{$\begin{array}{c}\text { MRR } \\
\left(\mathrm{cm}^{3} / \mathrm{min}\right)\end{array}$} & 4.95 \\
\hline 5 & - & - & 693 & 0.38 & - & - & & 5.14 \\
\hline 6 & - & - & - & - & 463 & 0.37 & & 5.54 \\
\hline
\end{tabular}

[6] Neşeli S., Yaldız S., Türkeş E., "Optimization of tool geometry parameters for turning operations based on the response surface methodology", Measurement, Vol. 44, No. 3, pp. 580-587, 2011.

[7] Knight W.A., Boothroyd G., "Fundamentals of metal machining and machine tools", Vol. $198,2005$.

[8] Imran M., Mirza J., Ahmad, W., "Sustainability assessment for dry, conventional and cryogenic machining in face milling of Ti-6Al-4V", Mehran University Research Journal of Engineering \& Technology, Vol. 36, No. 2, pp. 309-320, 2017.

[9] Munawar M., Mufti N. A, Iqbal, H., "Optimization of surface finish in turning operation by considering the machine tool vibration using Taguchi method", Mehran University Research Journal of Engineering and Technology, Vol. 31, No. 1, pp. 51-58, 2009.

[10] Chakraborty P., Asfour S., Cho S., Onar A., Lynn M., "Modeling tool wear progression by using mixed effects modeling technique when end-milling AISI 4340 steel", Journal of Materials Processing Technology, Vol. 205, No. 1-3, pp. 190-202, 2008.

[11] Gopalsamy B. M., Mondal B., Ghosh S.,
"Optimisation of machining parameters for hard machining: grey relational theory approach and ANOVA", The International Journal of Advanced Manufacturing Technology, Vol. 45, No. 11-12, pp. 10681086, 2009.

[12] Ding T., Zhang S., Wang Y., Zhu, X., "Empirical models and optimal cutting parameters for cutting forces and surface roughness in hard milling of AISI H13 steel", The International Journal of Advanced Manufacturing Technology, Vol. 51, No. 1-4, pp. 45-55, 2010.

[13] Suresh R., Basavarajappa S., Gaitonde V. N. Samuel G. L., "Machinability investigations on hardened AISI 4340 steel using coated carbide insert", International Journal of Refractory Metals and Hard Materials, Vol. 33, pp. 75-86, 2012.

[14] Das S. R., Kumar A., Dhupal D., "Effect of machining parameters on surface roughness in machining of hardened aisi 4340 steel using coated carbide inserts", International Journal of Innovation and Applied Studies, Vol. 2, No. 4, pp. 445-453, 2013.

[15] An Q., Wang C., Xu J., Liu P., Chen M., "Experimental investigation on hard milling of high strength steel using PVD-AlTiN coated cemented carbide tool", International 
Journal of Refractory Metals and Hard Materials, Vol. 43, pp. 94-101, 2014.

[16] Senthilkumar N., Tamizharasan T., Gobikannan S., "Application of response surface methodology and firefly algorithm for optimizing multiple responses in turning AISI 1045 steel", Arabian Journal for Science and Engineering, Vol. 39, No. 1, pp. 8015-8030, 2014.

[17] Azam M., Jahanzaib, M., Wasim, A. and Hussain, S., "Surface roughness modeling using RSM for HSLA steel by coated carbide tools", The International Journal of Advanced Manufacturing Technology, Vol. 78, No. 5-8, pp. 1031-1041, 2015.

[18] Lauro, C.H., Filho, S. L. M. R., Baldo, D., Cerqueira, S. A. A. D. G. and Brandao, L. C., "Optimization of micro milling of hardened steel with different grain sizes using multiobjective evolutionary algorithm", Measurement, Vol. 85, pp. 88-99, 2016.

[19] Hassanpour, H., Sadeghi, M. H., Rasti, A. and Shajari, S., "Investigation of surface roughness, microhardness and white layer thickness in hard milling of AISI 4340 using minimum quantity lubrication", Journal of Cleaner Production, Vol 120, pp. 124-134, 2016.

[20] Abbas A. T., Ragab A. E., Bakhali E. A. A., Danaf, E. A. E., "Optimizing cutting conditions for minimum surface roughness in face milling of high strength steel using carbide inserts", Advances in Materials Science and Engineering, Vol. 2016, pp. 114, 2016.

[21] Antony S. D., Godwin A . A., , V. D. V., "Investigation and Prediction of Material Removal Rate and Surface Roughness in CNC Turning of EN24 Alloy Steel", Asian Journal of Research in Social Sciences and Humanities, Vol. 6, No. 8, pp. 849-863, 2016.

[22] Kumar S., Singh D., Kalsi, N. S., "Analysis of Surface Roughness during Machining of Hardened AISI 4340 Steel using Minimum Quantity lubrication", Materials Today: Proceedings, Vol. 4, No. 2, pp. 3627-3635, 2017.

[23] Khan P. L., Bhivsane S. V., "Experimental
Analysis and Investigation of Machining Parameters in Finish Hard Turning of AISI 4340 Steel", Procedia Manufacturing, Vol. 20, pp. 265-270, 2018.

[24] Muaz M., Choudhury S. K., "Experimental Investigations and Multi-objective Optimization of MQL-Assisted Milling Process for Finishing of AISI 4340 Steel", Measurement, Vol. 138, pp. 557-569, 2019.

[25] Benedicto E., Carou D., Rubio E., "Technical, economic and environmental review of the lubrication/cooling systems used in machining processes", Procedia Engineering, Vol. 184, pp. 99-116, 2017.

[26] Ness B., Piirsalu E. U., Anderberg S., Olsson L., "Categorising tools for sustainability assessment", Ecological Economics, Vol. 60, No. 3, pp. 498-508, 2007.

[27] Goindi, G.S. and Sarkar, P., "Dry machining: A step towards sustainable machiningChallenges and future directions", Journal of Cleaner Production, Vol. 165, pp. 15571571, 2017.

[28] Sreejith P. S., Ngoi B. K. A., "Dry machining: machining of the future", Journal of Materials Processing Technology, Vol. 101, No. 1-3, pp. 287-291, 2000.

[29] Lawal S.A., Choudhury I. A., Nukman Y., "A critical assessment of lubrication techniques in machining processes: a case for minimum quantity lubrication using vegetable oilbased lubricant", Journal of Cleaner Production, Vol. 41, pp. 210-221, 2013.

[30] Hyatt, M., Caton, R. and Lovell, D., "Advanced materials development in commercial aircraft", Aircraft Design and Operations Meeting, 2012.

[31] Lovell D., Disotell M., "Structural material trends in commercial aircraft", Proceedings of the International Conference on Air Transportation: Technical Perspectives and Forecasts, 2012

[32] Samayapuram T., "Investigation and Prediction of Material Removal Rate and Surface Roughness in CNC Turning of EN24 Alloy Steel", Mechanics and Mechanical Engineering, Vol, 20, No. 4, pp. 451-466, 2016. 
[33] Natarajan U., Periyanan P., Yang S. H., "Multiple-response optimization for microendmilling process using response surface methodology", The International Journal of Advanced Manufacturing Technology, Vol. 56, No. 1-4, pp. 177-185, 2011.

[34] Witek-Krowiak A., Chojnacka K., Podstawczyk D., Dawiec A., Pokomeda, K., "Application of response surface methodology and artificial neural network methods in modelling and optimization of biosorption process", Bioresource Technology, Vol. 160, pp. 150-160, 2014.

[35] Behera S.K., Meena H., Chakraborty, S. and Meikap, B. C., "Application of response surface methodology (RSM) for optimization of leaching parameters for ash reduction from low-grade coal", International Journal of Mining Science and Technology, Vol. 28, No. 4, pp. 621-629, 2018.

[36] Montgomery D.C., "Design and Analysis of Experiments with Design Expert Software", John Wiley and Sons, 2004. 